\title{
Mobile Neural Networking Hypothesis for Complex Concept and Its Logical Structure (Digital Linguistics)
}

\author{
Kumon Tokumaru
}

\begin{abstract}
Digital Linguistics (DL) proposes that (1) mobile neural networks among immune cells inside ventricle system (VS) are in charge of sign reflex and linguistic processing, and (2) mobile neurons, currently designated as B lymphocytes, floating in cerebrospinal fluid (CSF) function as concept devices. 530 MA (Million years ago), mobile neurons evolved from neurons to network flexibly with various terminals on the ventricle wall without synaptic connections. With the acquisition of logical property phonemes by linguistic humans, mobile neurons started to function as signs thinking with words, namely concepts. DL identifies that there are several different complexity orders in concepts, and that Forward Error Correction (FEC) should be implemented against incoming linguistic information.
\end{abstract}

Index Terms-Complex concept, complexity order, forward error correction, mobile neuron, sign reflex.

\section{INTRODUCTION}

Digital Linguistics (DL) is an interdisciplinary study that identifies human language as a digital evolution of mammal analog vocal sign communications. Analog signs are unique with their sound waveforms but limited in number, whilst human digital word signs are infinite by permutation of their logical property, phonemes. The digital system consists of autonomous logical networks to regulate information and generate complexity: computer networks and reproduction/evolution of living organism are digital. Inheritance and development of collective human intelligence should also be understood as digital [1].

The complexity of linguistic information and human intelligence can be visualized with reference to the OSI (Open System Interconnection) Reference Model combined with noise factors in the General Communication Model (Fig. 1) [2], [3]. As our brain processes linguistic information word by word, diagrams indicating overall picture, multiple layer structures and interrelationship among linguistic elements should be referred to a reference model. Fig. 1 divides linguistic communication into low noise logical layers and noisy physical layers. Logical layers are inside the brain, and the physical layer is outside. Fig. 1 displays linguistic information transferred from teacher to pupil taking noise factors into account.

Manuscript received April 9, 2019; revised May 21, 2019.

Kumon Tokumaru is with KOKU, Japan (e-mail: kalahari145ma@y-mobile.ne.jp).

\section{Mobile Neuron as a Conceptual Device}

\section{A. Counter Evidence for Cortical Synaptic Connection Hypothesis Recorded by Pavlov}

The brain mechanism for linguistic processing has not yet been clarified or even hypothesized. Scientists discuss the "Language Acquisition Device" or "Linguistic Brain" without identifying the organ and its cellular/molecular level mechanism. As the neocortex anomalies in the Broca / Wernicke areas were observed in the post mortem examination of patients with speech impediments, it is taken as granted that linguistic processing takes place on the neocortex by establishing sensor-motor synaptic connections. But in fact, there is no evidence or cellular/molecular identification on the neocortex.

Pavlov had also supposed that conditioned reflexes are established as synaptic connections between sensory and motor areas on the cortex. [4] To demonstrate that " $(A)$ decerebrate dog would never have responded by salivary secretion to any stimulus of the kind." he removed the sensory areas or cerebral cortex entirely. (Lecture-1/-2) However his writings in Lecture-19/20/21 contradict his statement in Lecture-1/-2. "The first change which follows the extirpation of some part of the cortex is the almost invariable disappearance of conditioned reflexes; but in the majority of cases it is only the 'artificial' conditioned reflexes which disappear, i.e. those which were established in the laboratory, being therefore relatively recent and little practiced. If the 'natural' conditioned reflexes have also disappeared, they are always the first to reappear; but usually no disappearance of the natural conditioned reflexes could be observed even though tested immediately after the recovery from the anaesthetic administered during the operation. ... As a rule the conditioned reflexes disappear after the operation, whether it is performed on one or both of the hemispheres and on whatever portion of them it is carried out. The absence of 'artificial' reflexes persists for different lengths of time, varying from a single day to several months." (Lecture-19)

It is plausible that Pavlov had realized the above contradiction, but that he just presented the contradicting theory and experimental result as they were without his comments. Probably he did not want to make things complicated, and honestly confessed in Lecture-22: "Indeed I have no doubt that the presentation of the subject matter attempted in these lectures will in the future still be corrected in many details. Errors in interpretation, and errors sometimes in the methods of observation, are naturally to be expected in a study of such astounding complexity." It is our responsibility to identify his mistakes, correct them and 
enhance collective human intelligence.

\section{B. Mobile Ad-Hoc Networking Neurons}

Pavlov had no alternative idea on the mechanism for sign reflexes. The author has been proposing the immune cell networking hypothesis inside CSF in VS internationally since 2013 [5], [6]. To date, not a single opposite opinion or disproof has been raised. This hypothesis is based on two lectures of Jerne delivered in 1974 and 1984 [7], [8].

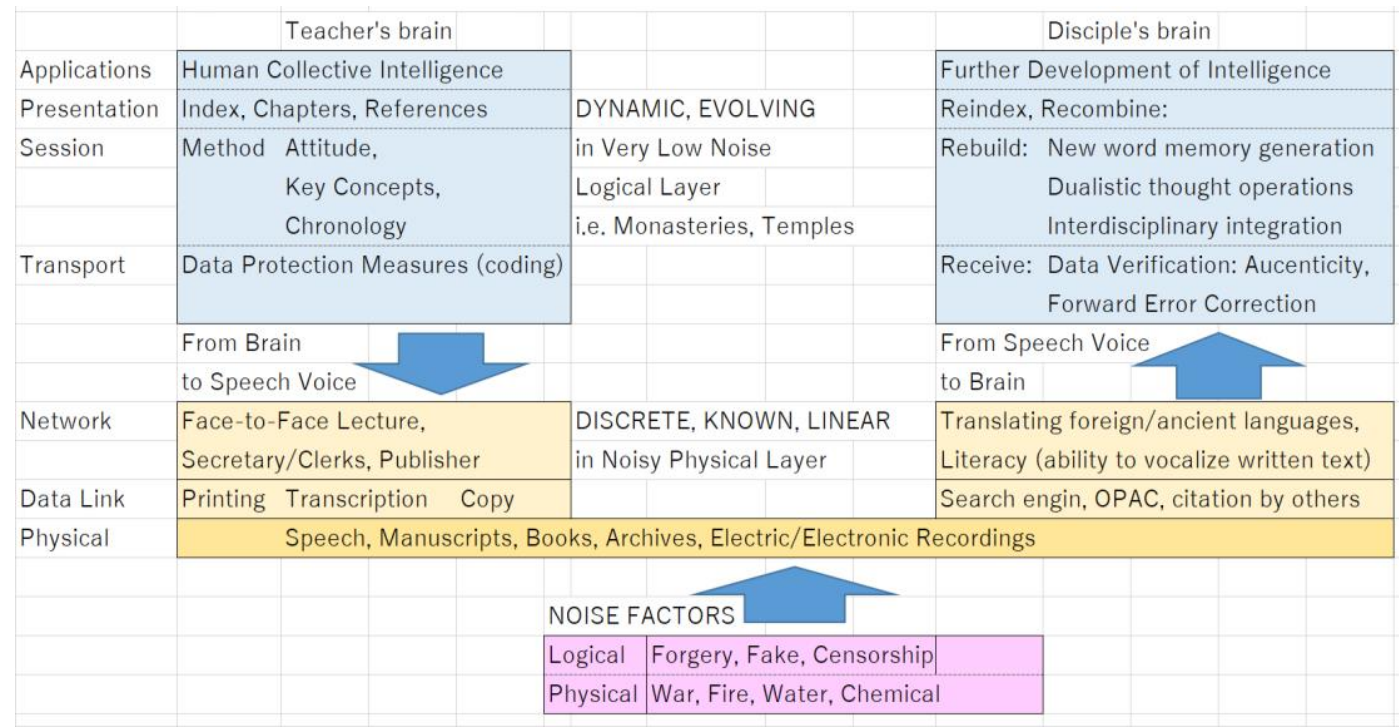

Fig. 1. Human intelligence analysis based on OSI reference model with noise factors.

Jerne at the end of his lecture, "Toward the Network Theory of Immune System", for which he was awarded the Noble prize, stated that "immune system ... bears a striking resemblance to the nervous system. ..... Both systems display dichotomies and dualisms. The cells of both systems can receive as well as transmit signals. In both systems the signals can be either excitatory or inhibitory."

Dichotomy divides the world into two, A or not-A, and executes pattern recognition. Dualism allows one to formulate a logic which receives any arbitrary two signals and produces an output. "The two systems penetrate most other tissues of our body, but they seem to be kept separate from each other by the so-called blood-brain-barrier. The nervous system is a network of neurons in which the axon and the dendrites of one nerve cell form synaptic connections with sets of other nerve cells. In the human body there are about $10^{12}$ lymphocytes as compared to $10^{10}$ nerve cells. Lymphocytes are thus a hundred times more numerous than nerve cells. They do not need connections by fibres in order to form a network. As lymphocytes can move about freely, they can interact either by direct encounters or through the antibody molecules they release. The network resides in the ability of these elements to recognize as well as to be recognized." [7].

If the logic of dichotomy/dualism and transmitting/receiving functions are the same, and only networking methods are different, we had better rename immune cells "Mobile Ad-hoc Networking (MANet) Neurons" or simply "Mobile Neurons".

Jerne demonstrated, in his Nobel lecture, "The Generative Grammar of the Immune System", that the immune system has necessary properties required for linguistic processing. The immune system is capable of generating more than ten million pairs of specificity combinations (key and key hole pairs), and "the immune system will then produce antibodies that specifically recognize these molecules, even if they have been synthesized in a chemical laboratory without ever before having existed in the world." [8].

$\mathrm{B}$ and $\mathrm{T}$ lymphocytes are thought to be immune cells, which fight against pathogens inside blood vessels. They were born 530MA (million years ago) with the birth of vertebrates, the ventricle system and cerebrospinal fluid (CSF) [9]. It is plausible that they were first born as MANet (Mobile Ad-hoc Networking) Neurons to enable flexible networking inside the ventricle system, then later started immune activities.

"The ventricle system is filled with CSF. CSF is weak alkaline and transparent aqueous solution. This fluid is filtered at choroid plexus and fills the ventricle system, circulates CNS, goes through hindbrain median opening and hindbrain outside ports of the fourth ventricle and arrives at subarachnoid space to be absorbed by vein system." [10]. CSF is the third circulatory system next to the blood and lymph systems. The size of the VS is approximately $150-160$ $\mathrm{ml}$ and about $500-600 \mathrm{ml} \mathrm{CSF}$ is filtered every day by the Choroid Plexus (CP) at each ventricle: CSF changes $3-4$ times every day. CSF is secreted blood sent via the CP artery. The CP filtrates the blood and prevents large molecules from entering into the ventricular system, making a so-called Blood Brain Barrier (BBB). Until recently, thanks to the BBB, lymphocytes and immunoglobulins were not supposed to be in CSF. It now becomes clear that they exist at the rate of $0.5 \%$ of their amount in the blood, and perform active immune responses.

The route of CSF is through the Frontal Lobe, Corpus Callosum, Fornix, Ventriculi Lateralis (Hippocampus), Temporal Lobe, Thalamus, Hypothalamus, Cerebellum, Medulla Oblongata and the Cortex in the Subarachnoid Space. CSF is in contact with almost all parts of the brain, and connects the Limbic System to the Neocortex. This route is the "Information Super Highway" inside the brain system, and it demonstrates that lymphocytes floating inside CSF can network with any part of the brain system. 


\section{Inside VS Mobile Neural Networks}

There are not well recognized neurons inside the ventricle system named as Cerebrospinal Fluid Contacting Neurons (CSF-CN) [11]. CSF-CN are neurons connecting the retina/cochlea and ventricle wall. Their terminals at the ventricle wall constitute epitopes (= antigens) with cilium of motor protein on the top. It is plausible that CSF-CN has functions to generate a new antigen terminal at the Brainstem Ascending Reticular Activating System (ARAS) corresponding to a new external sign stimulus shape or waveform and to stimulate B lymphocytes floating in CSF (Fig. 2).

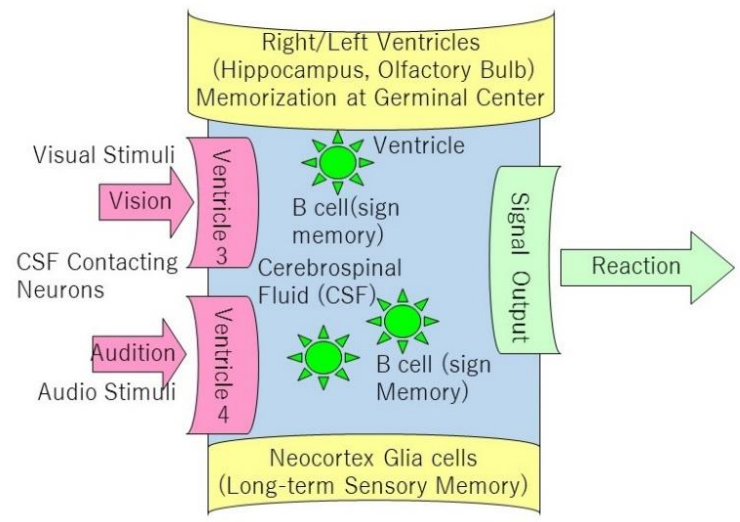

Fig. 2. Schematic Model for Mobile Neural Network inside CSF/VS

About $90 \%$ of brain cells are immune cells. The gray material which covers the surface of neocortex is microglia. Microglia is very similar to macrophage which presents various immune network terminals on their cell membrane. It is possible that, when a memory cell (microglia) is newly matured in the Hippocampus with sensory memory, antigen 3-dimensional structure with specificity to an antibody of concept device is presented on the cell membrane surface.

After reviewing the versatility of its logics and the fulfilment of network requirements, the author implemented the Network Requirement Analysis among CSF-CN, microglia and mobile B lymphocytes, and the author is more convinced than before that linguistic activities and intelligence are inside the ventricular system neuro-immune networks. (Table I)

\begin{tabular}{|c|c|c|c|c|c|}
\hline \multirow{2}{*}{\multicolumn{6}{|c|}{$\begin{array}{l}\text { Network Requirement Analysis for Inside Ventricle System Immune Cell } \\
\text { Networks for Word Sign Reflex }\end{array}$}} \\
\hline & & & & & Mobility \\
\hline $\begin{array}{l}\text { CSF (Cerebro- } \\
\text { spinal Fluid) } \\
\text { Contacting } \\
\text { Neuron }\end{array}$ & $\begin{array}{l}\text { Sound Waveform of } \\
\text { word phonetics (\& } \\
\text { Instinctive Reflex) }\end{array}$ & Activation & $\begin{array}{l}\text { Antigen terminal } \\
\text { with cilial vector }\end{array}$ & $\begin{array}{l}\text { Brainstem } \\
\text { Reticular } \\
\text { Formation }\end{array}$ & Fixed \\
\hline $\begin{array}{l}\text { B lymphocyte } \\
\text { (= Concept } \\
\text { Device) }\end{array}$ & $\begin{array}{l}\text { Word Networking } \\
\text { Results and } \\
\text { Waveform } \\
\text { Receptors }\end{array}$ & $\begin{array}{l}\text { Active / } \\
\text { Passive }\end{array}$ & $\begin{array}{l}\text { Antibody ( }=3 \\
\text { Antigen CDRs) }\end{array}$ & $\begin{array}{l}\text { Floating inside } \\
\text { CSF (Cerebro- } \\
\text { spinal Fluid) }\end{array}$ & Mobile \\
\hline $\begin{array}{l}\text { Microglia Cell } \\
(=\text { Meaning of } \\
\text { Daily Concept) }\end{array}$ & $\begin{array}{l}\text { Sensory Memories } \\
\text { with Sound } \\
\text { Waveform as } \\
\text { indexes }\end{array}$ & Passive & $\begin{array}{l}\text { Antigen terminal } \\
\text { to be recognized }\end{array}$ & Neocortex & Fixed \\
\hline
\end{tabular}

\section{Evolution from Reflexive Sign to Concept}

DL hypothesizes that a microbe, namely B lymphocyte, for sign reflex functions as a conceptual device. But the functions of reflexive signs and those of conceptual devices are not the same. It is necessary to examine how such an evolution could take place.

There are no established and shared definitions for a "reflexive sign mechanism" and a "concept (device)". The former responds to a certain sound waveform or visual shape, and releases a predetermined action. The latter is a device representing a word sign phonology, to be activated with the logic of dichotomy. It networks with relevant sensory memories as well as other word signs exploiting the logic of dualism. At each networking and recognition, the evaluation is made and its results such as $=, \neq, \leqq,<<, \infty, \equiv, \odot, \bigcirc, \times$, $\triangle, \cap, \cup, \fallingdotseq, \subset, 1 / 4,1 / 2$, etc. are memorized. After sufficient networking and thought operations, a concept consists of a group representing networking/thought memories, and can be put into another dualistic thought operation.

The logic of sign reflex is both a dichotomy (to determine A) and dualism (If A then do B). The same logic serves for proper nouns. (If A then recall B) "If A then B" dualism has one-to-one connectivity, and there is no thought or generalization element. In the author's definition, a proper noun is not a concept.

It is probable that an infant would perceive any word as a proper noun. At a certain age or occasion, they may become embarrassed to discover that most nouns are not proper nouns but concepts, which are products of generalization. In order to overcome this embarrassment, the child tries to extract and apply rules of generalization in a trial-and-error manner. At this moment, a microbe, B lymphocyte, starts thought operations and becomes a concept.

A concept can also be operated with the logic of dichotomy (to determine $\mathrm{A}$ ) and dualism $(\mathrm{A}+\mathrm{B}=\mathrm{C})$. Thought operation is " $\mathrm{A}+\mathrm{B}=\mathrm{C}$ " dualism. It is critically important that a concept accumulates, generalizes and represents results of thought operations. Thus they can be treated in accordance with a group theory in mathematics. Piaget (1947) listed five conditions to verify the correctness of conceptual meanings. of (i) combinativity, (ii) reversibility, (iii) associativity, (iv) general operation of identity, and (v) tautology or special identities [12]

(I) Combinativity: $\mathrm{x}+\mathrm{x}^{1}=\mathrm{y} ; \mathrm{y}+\mathrm{y}^{1}=\mathrm{z}$; etc.

(II) Reversibility: $\mathrm{y}-\mathrm{x}=\mathrm{x}^{1}$ or $\mathrm{y}-\mathrm{x}^{1}=\mathrm{x}$.

(III) Associativity: $\left(x+x^{1}\right)+y^{1}=x+\left(x^{1}+y^{1}\right)=(z)$.

(IV) General operation of identity: $x-x=0 ; y-y=0$; etc.

(V) Tautology or special identities: $\mathrm{x}+\mathrm{x}=\mathrm{x}$; $\mathrm{y}+\mathrm{y}=\mathrm{y}$; etc.

A concept is an outcome of thought operations. As it is a word, it can be put into another thought operation as a source. J.v. Neumann mentioned a vicious circle mechanism to increase complexity and this idea seems to have developed into "fractal" of Mandelbrot, his last disciple [13]. The author supposes that the logic of dichotomy and dualism in B lymphocytes can perform such vicious circles, and hypothesized that complexity of meanings increases step by step with synergetic manner or exponentially.

\section{COMPLEXITY ORDERS OF CONCEPTS}

\section{A. Pioneering Study by Vygotsky}

There are not many discussions about complex, abstract or scientific concepts in linguistics. Russian psychologist 
Vygotsky made an extensive study on "The Development of Scientific Concepts in Childhood", and identified the intellectual functions required for the acquisition of scientific concepts: a concept is more than the sum of certain associative bonds formed by memory, more than a mere mental habit; it is a complex and genuine act of thought that cannot be taught by drilling, but can be accomplished only when the child's mental development itself has reached the requisite level. At any age, a concept embodied in a word represents an act of generalization. But word meanings evolve. When a new word has been learned by the child, its development is barely starting; the word at first is a generalization of the most primitive type; as the child's intellect develops, it is replaced by generalization of a higher and higher type - a process that leads in the end to the formation of true concepts. ...." [14].

The development of concepts, or word meanings, presupposes the development of many intellectual functions; deliberate attention, logical memory, abstraction, the ability to compare and to differentiate. These complex psychological processes cannot be mastered through initial learning alone. If there are several requisite psychological levels in the formation of daily and logical concepts, what are the differences among complex concepts? The author surmises that the difference of complexity is attributable to the number of generalization or conceptualization cycles (Table II).

\begin{tabular}{|c|c|c|c|c|c|c|c|}
\hline C.O. & Sign Word (Concept) Types & $\begin{array}{l}\text { Meanings (Networking of } \\
\text { Memories) }\end{array}$ & $\begin{array}{l}\text { Noise } \\
\text { Level }\end{array}$ & $\begin{array}{l}\text { Accura } \\
\text { cy }\end{array}$ & $\begin{array}{l}\text { Exampl } \\
\text { es }\end{array}$ & $\begin{array}{l}\text { Phyloge } \\
\text { ny }\end{array}$ & $\begin{array}{l}\text { Ontoge } \\
\text { ny }\end{array}$ \\
\hline 0 & $\begin{array}{l}\text { Reflexive Sign (Magic, } \\
\text { Emergency), Proper noun }\end{array}$ & $\begin{array}{l}\text { If A Then B behavior/memory } \\
\text { (Evacuation, Consumption, ) }\end{array}$ & high & $\begin{array}{l}\text { devotio } \\
n\end{array}$ & $\begin{array}{l}\text { Tsuna } \\
\text { mi }\end{array}$ & $\begin{array}{l}66 \mathrm{MA} \text { or } \\
72 \mathrm{KA}\end{array}$ & baby \\
\hline 1 & $\begin{array}{l}\text { Daily Spontaneous Concept } \\
\text { (DSC) }\end{array}$ & $\begin{array}{l}\text { Recalling relevant Sensory } \\
\text { memories stored at Microglia }\end{array}$ & $\begin{array}{l}\text { ambien } \\
\mathrm{t}\end{array}$ & $\begin{array}{l}\text { egocen } \\
\text { tric }\end{array}$ & Apple & $66 \mathrm{KA}$ & child \\
\hline 2 & Primary Logical Concept (PLC) & Thought operations of DSC & $\begin{array}{l}\text { ambien } \\
\mathrm{t}\end{array}$ & $\begin{array}{l}\text { ego- } \\
\text { logical }\end{array}$ & Citrus & $5 \mathrm{KA}$ & $\begin{array}{l}\text { school } \\
\text { boy }\end{array}$ \\
\hline 3 & $\begin{array}{l}\text { Complex Logical Concept(CLC) } \\
\text { with definitions }\end{array}$ & Thought operations of PLC, DSC & low & $\begin{array}{l}\text { orthogr } \\
\text { aphy }\end{array}$ & Instinct & $2 K A$ & $\begin{array}{l}\text { philoso } \\
\text { pher }\end{array}$ \\
\hline 4 & $\begin{array}{l}\text { True Scientific Concept to } \\
\text { describe complexity }\end{array}$ & $\begin{array}{l}\text { Thought operations of CLC, PLC, } \\
\text { DSC }\end{array}$ & $\begin{array}{l}\text { extrem } \\
\text { ely low }\end{array}$ & $\begin{array}{l}\text { regene } \\
\text { rative }\end{array}$ & $\begin{array}{l}\text { Reprod } \\
\text { uction }\end{array}$ & $\begin{array}{l}21 \text { st } \\
\text { century }\end{array}$ & $\begin{array}{l}\text { scienti } \\
\text { st }\end{array}$ \\
\hline
\end{tabular}

\section{B. Level-0 Sign and Proper Noun}

Level-0 is not conceptual. The words invoke physical actions such as emergencies, incantations, consumption signs etc. "If A then B", a linear, determined and thoughtless logic, is applied. It functions in noisy environment under stresses and pressures. Examples are evacuation orders in an emergency, oracles of consumption, or proper nouns.

Ontogenetically it corresponds to a baby, who considers words as proper nouns. For them, words such as "papa" and "mama" are exclusively connected to their own parents.

\section{Level 1 Daily Spontaneous Concept (DSC)}

At a certain time, infants learn that there are other "papas" and "mamas", and they are embarrassed and forced to think. "Why this man is papa?", "He is not papa", "A girl next to me called him papa, what is papa?" etc. When a word ceases to be a proper noun, it becomes independent from particular memories, but networks with various memories and words. Conceptualization is generalization by thinking.

Level-1 concepts connect a word sign to multiple sensory memories with logical memories, i.e. "yes" and "no": an audio input of a word sign recalls a generalized conceptual memory. A vision or an audition recalls a word sign. At each connection, a positive or negative thought result is accompanied. A daily spontaneous concept (DSC) is obtained by a child in this way. The meanings of daily concepts are individual experience memories, which may vary by timing, location and other conditions.

The logic for thought and networking can be both dichotomy and dualism, which indicates that non-human animals can share DSC with linguistic humans very easily. The critical difference is the use of phonemes, which non-human animals can recognize but cannot vocalize. Through daily experiences and learning, one can acquire a new concept with relevant sensory/networking memories. In accordance with the accumulation of experiences, concepts are classified and categorized through mutual networks into a non-hereditary concept system of an individual and independent person.

\section{Level 2 Primary Logical Concept (PLC)}

Level-2 is for concepts made of single conceptual operations of DSCs, such as AND, OR and NOT. Thought operations of DSCs can yield yet more complex concepts, namely Primary Logical Concepts. (PLC) For example, AND operation of "butterfly" AND "caterpillar" yields "larva", which is a concept of relationship. OR operation of "lemon" OR "orange" yield "citrus", a concept of class.

The above primary logical concepts do not directly relate to perceptible objects, but to a relationship between two concepts or extracted commonality in a class. The author assigns complexity order 2 for PLC, because it is an extra generalization over a generalization made at DSC.

\section{E. Level 3Complex Logical Concept (CLC)}

Level-3 is for scientific terms with transparent definitions and open access for their source in respective disciplines. At this level, words are memorized and used with correct spelling, and other conventions. Third order concepts are no more spontaneous. They are no more sensible: they are conceptual. They are generated through multiple thought operations. The results of meaningful thought operations constitute a group, which is the meaning of CLC.

The complexities of DSC, PLC and CLC are similar to those of dimensions, mono-dimensional linear, two- 
dimensional square and three-dimensional cubic. The guiding principle to understand a digital system is "signal-to-noise ratio" in classical communication theory [13]. The dynamic capacity of the signal is inversely proportional to the noise level. When the noise level is low, dynamic phenomena can take place. This explains the complex regulation and self-organization in complex and self-organizing digital system. VS and CSF are located at the deepest part of the brain, and they constitute a low noise environment. Scientific thoughts such as Copernican theory and Mendel's law were conceptualized in monasteries, a low noise environment.

As the meaning of CLC concept is not endorsed by sensory memories but constitutes of networking memories of thought operations, it is necessary to think correctly.

\section{F. Level 4 True Scientific Concept (TSC)}

True scientific concepts (TSC) are interdisciplinary applicable concepts with universal and transparent definitions. They are generated by step-by-step logical thought operations Therefore, although they are highly abstract at a glance, they can be dismantled and built-up with simple and basic operations. At the bottom, they are endorsed by reality. When we establish collective human intellectual genomes, TSCs should be used.

TSC is interdisciplinary and represents complexity, which can be defined with absolute coordinates such as geo-coordinates, molecular structures and phylogenetic/ ontogenetic time frames, etc. The meanings of TSC is ever progressing, being updated and integrated with the latest interdisciplinary discoveries.

\section{FORWARD ERROR CORRECTION OF LINGUISTIC INFORMATION}

The sign reflex is an autonomous and involuntary mechanism. As it is not equipped with circuit self-diagnosis mechanism, thought operations should be deliberately implemented. To verify and rectify the meanings of concepts, a group theory of mathematics should be applied.

As sign reflex responds reflexively to incoming sign without verifying its correctness, we had better implement Forward Error Corrections (FEC) at each reception. Errors in linguistic information can be divided into Channel Coding Errors, for which authors are not responsible, and Source Coding Errors, for which authors are responsible. As they constitute the excluded middle, we can get error free information after FEC. With channel coding error correction, the authentic text of authors can be recuperated. By intensively reading the authentic text, authors' misunderstanding and mistakes should be identified and corrected [15].

\section{CONCLUSION}

When mammal vocal communication mechanism is identified as the sign reflex inside CSF/VS, and human language is analyzed as digital system, a hypothesis for the meaning mechanism of complex concepts was obtained. In the era of internet and worldwide web, linguistic humans must overcome the restrictions of sign reflex mechanism to enhance learning and thinking ability. The author hopes and believes that the hypotheses in DL should be useful for the establishment of collective human intellectual genomes.

\section{ACKNOWLEDGMENT}

I am grateful to various study groups in IEICE, the Institute of Electronics, Information and Communication Engineers, and in IPSJ, the Information Processing Society of Japan, where most of my preliminary and premature ideas were presented and have been discussed since 2008.

\section{REFERENCES}

[1] K. Tokumaru, "A mobile hypothesis of neural networks for spinal reflex and linguistic processing (digital linguistics)," Linguistics and Literature Studies, vol. 6, pp. 267-277, 2018.

[2] C. E. Shannon, "A mathematical theory of communication," The Bell System Technical Journal, vol. 27, pp. 379-423/623-656, 1948.

[3] A. S. Tanenbaum and D. J. Wetherall, Computer Networks, 5st ed. Prentice Hall, 2011.

[4] I. P. Pavlov. (1927). Conditioned Reflexes. translated by G. V. Anrep [Online]. Available: http://psychclassics.yorku.ca/Pavlov/index.ht

[5] K. Tokumaru and Y. Nagashima, "Exploitation of the both variable and constant regions of immunoglobulin molecular structure for a concept and grammar complex - The human consciousness as immune networks inside cerebrospinal fluid (CSF) in the ventricular system (VS) hypothesis," in Proc. 19th ICL, 2013.

[6] K. Tokumaru, "The digital language operated by logical syllables Hypotheses for the origin and mechanism of human language," in Proc. 19th ICL, 2013

[7] N. K. Jerne, "Toward a network theory of immune system," Ann Immunol (Paris), vol. 125, no. 1-2, pp. 373-389, 1974.

[8] N. K. Jerne, "The generative grammar of the immune system (The Nobel Lecture)," Bioscience Reports, vol. 5, issue 6, pp. 439-451, June 1985.

[9] P. Kourilsky, Les Jeux de Hazard et de la Complexité - La Nouvelle Science de L'immunologie, Japanese translation by H. Yakura, Paris Odile Jacob, Tokyo, Misuzu, 2018.

[10] T. Tamotsu, E. Kawano, and Y. Haida, "Sensory organ in the ventricle System: Paraventricular organ," Comparative Physiological Chemistry, vol. 23, pp. 143-152, 2006.

[11] B. Vígh, M. J. M. Silva, C. L. Frank, C. Vincze, S. J. Czirok, A. Szabó, A. Lukáts, and A. Szél, "The system of cerebrospinal fluid-contacting neurons. It's supposed role in the nonsynaptic signal transmission of the brain," Histol Histopathol, vol. 19, pp. 607-628, 2004.

[12] J. Piaget, La Psychologie de L'intelligence, Paris, Armand Colin, 1947.

[13] J. Neumann, "The general and logical theory of automata," presented at the Hixon Symposium, 1951.

[14] L. Vygotsky, Thought and Language. 1935.

[15] K. Tokumaru, "Forward error correction of linguistic information (digital linguistics) - Dividing errors by author's responsibility and irresponsibility,” IEICE Tech Repo LOIS 2018-16.

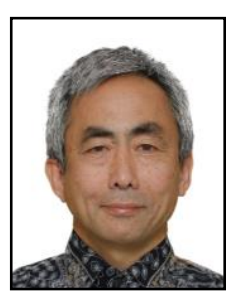

Kumon Tokumaru was born in 1959 in Oita, Japan. LLB from Univ, of Tokyo.

$\mathrm{He}$ has worked in the field of satellite earth observation and satellite communication. He has published books, "Dogen wo Yomitoku" in Japan in 2017, and "Digital Linguistics: The Brain Mechanism for Grammatical Processing", Lambert Academic Publishing, 2018. He visited the oldest modern human site in the world, Klasies River Mouth Caves in South Africa in 2007. Since then, he has been working on Digital Linguistics, starting from the origin of language, i.e. acquisition of logical properties of phonemes and morae, towards the completion of linguistic evolution, i.e. establishment of collective human intellectual genomes. 